\title{
CAPITALISMO E NOVOS NÔMADES EM DUBAI
}

Dubai: gilded cage. (2010). Syed Ali. New Haven e Londres:

Yale University Press, 240p.

Na cena árabe, uma zona de estabilidade parece alheia à onda recente de abalos da ordem política. Com a sexta maior reserva de petróleo do mundo, os Emirados Árabes são uma federação de monarquias tradicionais governados pela dinastia Al-Nahyan desde 1971, em solução de continuidade arranjada com o governo britânico. A despeito de importantes distinções entre si, os Emirados compartilham governo extremamente restritivo, estado de bem-estar para a diminuta população local e, em níveis variados, economia em processo de diversificação, com notável efeito de atração de profissionais estrangeiros. O fluxo da economia combina-se a impressionante fluxo de pessoas. Suas principais unidades federadas, Dubai e Abu
Dhabi, têm cerca de $90 \%$ da população constituída por estrangeiros em idade economicamente ativa e em condição temporária de residência.

$\mathrm{Na}$ escassa bibliografia sobre os Emirados Árabes, Dubai: gilded cage, de Syed Ali, constitui referência necessária. Publicado em 2010 pela Yale University Press, o livro reúne temas-chave para o entendimento sobre o fenômeno Dubai e, de modo associado, sobre os Emirados em geral. O autor não chega a tratar da recessão de 2008, que conduziu à reconfiguração do pacto federativo na região, com retrocesso da autonomia de suas partes e controle mais estreito do governo central em Abu Dhabi. Em momento anterior à crise, Ali se dedica aos contornos ambíguos de uma cena autoritária cuja propagan- 
da versa sobre imagens de liberdade individual. Num ambiente político restrito aos movimentos da família real, o imaginário constituído em torno do "venha, faça dinheiro e consuma" associa-se à ideia de lugar aberto onde "qualquer ideia pode virar realidade". O capitalismo ganhou versão icônica no Golfo Pérsico. A ousadia física e estética da arquitetura local tornou-se a imagem-síntese do Emirado em questão.

No texto de Ali, a narrativa sobre Dubai valoriza suas rígidas rotinas de controle social e exploração do trabalho estrangeiro. Nas últimas décadas, consecutivas à descoberta de petróleo na região, produziu-se distinção marcada entre três grupos sociais: cidadãos locais com benefícios do governo, estrangeiros com inserção privilegiada no mercado de trabalho e, na ponta da linha, com maioria numérica, estrangeiros com baixa qualificação e condições precárias de exercício profissional. Vítimas de violações reiteradas de direitos humanos, compõem um ambiente esvaziado de direitos civis e políticos. Sensível à contraface do desenvolvimento econômico pronunciado, Ali desenvolve seu argumento a partir da observação da segunda geração de não nacionais residentes no Emirado. A partir da sua condição de "permanente impermanência" o autor lança luz sobre a Dubai contemporânea.

Antes da sua versão global, Dubai era um centro comercial com importância regional. Em princípios do século XX, atraiu comerciantes persas-árabes e indianos para seu porto com isenção de taxas e distribuição de terras. Desde então, sua economia transitou entre legalidade e ilegalidade e envolveu contato estreito com países vizinhos. A inflexão rumo ao lugar de destaque na cena capitalista esteve sobretudo referida à efervescência da economia do petróleo nos anos 1970, mas também incluiu práticas comerciais não declaradas. Negociantes da cidade extraíram grande vantagem, por exemplo, da intermediação de bens entre Índia e Paquistão, valendo-se do rompimento de relações diplomáticas entre os dois países e dos vínculos remanescentes por necessidades comerciais. Também na altura do embargo norte-americano ao Irã, operadores econômicos em Dubai contornaram informalmente a situação de isolamento do país vizinho. A expansão das redes de infraestrutura - estradas, aeroporto e porto - garantiu excelentes condições para o contrabando de bens variados.

A permissividade dos poderes local e federal em relação aos movimentos da economia não é, contudo, irrestrita. Há distinção rígida entre bens passíveis e não passíveis de circulação extraformal. No caso das drogas, faz-se notar a feição autoritária do governo, com aplicação de penas duras e irrevogáveis a seus negociadores. As barreiras comerciais reais tendem a ser morais, portanto, e não legais.

Ao sondar a realidade dos estrangeiros residentes, Ali prossegue no tema dos limites da liberdade econômica. Embora atraia profissionais 
para posições de relevo, estimulados por salários extremamente competitivos no mercado internacional, o governo dos Emirados assegura-se de que o interesse estrangeiro não ofus que o interesse nacional. Com este propósito estabelece, por exemplo, que todos os negócios sediados no país tenham cidadãos nacionais como sócios majoritários, o que os exime de investimentos e limita a evasão de capital.

Entre as medidas de regulação do mercado, a mais extrema refere-se ao controle estrito da mão de obra estrangeira. A despeito do abismo econômico entre não nacionais residentes, todos compartilham a condição comum de estadia temporária, vinculada a emprego formal. Os vistos são concedidos a cada três anos para trabalhadores e suas famílias. A possibilidade de aquisição de cidadania ou residência permanente é remota e as regras para esta concessão não são claras, legadas, na prática, ao arbítrio pessoal dos membros da família real. Isto significa que a quase totalidade da população estabelece laços provisórios com a cidade. Mesmo as histórias de vida que se estendem por médio e longo termo têm a marca do transitório, pontuadas por níveis variados, mas constantes, de incerteza sobre o futuro. Embora exista um viés combinado de classe e nacionalidade nos processos de renovação de visto, nenhum indivíduo ou estrato social goza a priori de garantias de permanência. Para tratar dos estrangeiros em Dubai, portanto, Ali descarta o conceito de imigran- te pelo sentido de estabilidade que ele implica.

A experiência permanente da impermanência é vivida em expressão limite pelos filhos de não-nacionais nascidos nos Emirados. Tendo em vista que a cidadania é comunicada pela descendência, e não pelo local de nascimento, e, ainda, que a residência de maiores de idade é condicionada à inserção no mercado de trabalho - ou, alternativamente, no caso das mulheres, ao matrimônio com cidadão ou estrangeiro em situação regular -, muitos jovens nascidos e criados em Dubai têm que deixar a cidade caso não consigam filiar-se à rede formal de empregos. Muitos contornam precariamente a interdição trabalhando ilegalmente com visto de turista. Neste caso, convivem com a possibilidade real de serem banidos para seus países de ascendência. Em muitos casos, sequer conhecem o lugar de cidadania de seus pais e/ou têm conhecimento rudimentar do idioma. Segundo Ali, a considerar a fragilidade formal dos seus vínculos com Dubai, são "estranhos na sua própria terra".

Entre os estrangeiros com baixa qualificação para o trabalho - prostitutas, babás, empregadas domésticas, trabalhadores da construção civil e motoristas de táxi - o rigoroso regime de controle social pelo visto costuma implicar violação de códigos internacionais de direitos. A pressão de organismos estrangeiros fez o governo dos Emirados retroceder de práticas irregulares como o uso de mão de obra escrava infantil em corridas de 
camelo. As crianças jockeys, que permitem aos camelos correr mais em razão do seu pouco peso, são menos comuns hoje do que em outros tempos. A despeito disto, persistem rotinas de extorsão do trabalhador. $O$ sistema kafala, por exemplo, também empregado em outros Estados do Golfo árabe, vincula estreitamente empregado a empregador e cancela sua mobilidade no mercado de trabalho. Para evitar que abandonem o emprego e se lancem no mercado informal, empresas que importam trabalhadores - e parecem contar com o consentimento tácito do governo com seus métodos - confiscam passaportes na chegada, não pagam salários mensalmente e são coniventes com condições precárias de habitação e transporte. Neste ambiente, a indisciplina é punida com deportações temporárias ou, em casos considerados graves, permanentes. Uma vez que os custos de visto, viagem e recrutamento (este último, ilegal) são do próprio trabalhador, essa dinâmica de idas e vindas do país de origem institui condições ainda mais precárias de sobrevivência.

Quanto aos profissionais qualificados, beneficiados por padrão de vida mais alto do que poderiam aspirar em seus países, não temem a deportação como os demais. Embora a atribuição de salário não seja indiferente à nacionalidade - indianos e ingleses no exercício da mesma função, por exemplo, tendem a ser remunerados de modo diferenciado -, estrangeiros bem situados no mercado de trabalho não são objeto de precon- ceito social como domésticas, operários e outros. O texto de Ali conduz o leitor a supor que o baixo nível de angústia dos não-nacionais de altos estratos sociais é função, em medida significativa, da sua renúncia ou simples desinteresse por valores democráticos ocidentais. Em geral, afirma o autor, o governo não empreende esforços para garantir disciplina cívica e política entre estrangeiros que ocupam importantes cargos. O interesse mútuo garante certa "docilidade" nesta relação. Isto é, reconhece-se um regime de complementaridade entre o objetivo de desenvolvimento e estabilidade da cidade e do país, por parte dos governantes, e os objetivos individuais ou corporativos de progressão econômica. Toda ameaça à ordem formal instituída seria um ruído nesta situação de equilíbrio. Conforme Ali, para os estrangeiros que escolhem residência em Dubai, a ideia de liberdade tende a contornar sua versão política. Nas suas bolhas de sociabilidade, constituída por critérios de afinidade cultural, movem-se sem maiores constrangimentos físico ou moral e chegam mesmo a experimentar a sensação de "vida real em suspenso" (Sayed, 2010: 120). Na comunidade mais ampla, sem prejuízo de seu comportamento social insular, encontram condições desejáveis para movimentação dos negócios. Dado este regime de conveniências, portanto, o envolvimento com a política tende a ser desimportante, ou mesmo disfuncional.

Entre os estrangeiros, este alinhamento com o governo extrapola os 
segmentos mais abastados, privilegiados pela produção de riqueza. Entrevistada por Ali, uma indiana de baixo estrato social não lastima o governo autoritário. A corrupção no seu país é que inspira lamento. Não há no seu discurso a noção de falta ou ausência para descrever a experiência da política em Dubai.

Representações sociais deste tipo potencializam e são potencializadas por mecanismos de controle social geridos pelo governo, como os benefícios sociais, os vistos de trabalho e os sistemas de exploração econômica, referidos a cada um dos três grupos sociais que constituem a sociedade em tela - isto é, nacionais, estrangeiros com alta e baixa qualificação profissional, nesta ordem, sem prejuízo de zonas de interseção na incidência do controle. Embora haja fissuras no modelo, com dissonâncias internas e externas aos Emirados, os operadores da cena autoritária alcançaram importante esvaziamento da política.
Em Dubai: gilded cage, Ali traz valiosa narrativa sobre o estado da arte da sociedade, da economia e da política em um dos principais eixos do capitalismo na cena contemporânea, os Emirados Árabes, ainda marginais na agenda de reflexões das Ciências Sociais. A experiência de Dubai traz elementos para o debate sobre noções de liberdade, direitos e política em contextos autoritários.

Cristina Buarque de Hollanda é professora do Departamento de Ciência Política da Universidade Federal do Rio de Janeiro (UFRJ), mestre e doutora em Ciência Política pelo Instituto Universitário de Pesquisas do Rio de Janeiro (IUPERJ). Publicou Modos da Representação Política: o experimento da Primeira República brasileira (2009) e Teoria das Elites (2011). 